\title{
A comparison of interhemispheric transmission times in acallosals and normals
}

\author{
M. A. JEEVES, University of Adelaide, \\ Adelaide, South Australia 5001
}

Interhemispheric transmission times for unstructured visual information were measured in two patients born without the corpus callosum and compared with similar measures for groups of normals. The results support an earlier suggestion (Jeeves, 1965) that lengthened interhemispheric transmission times in acallosals may be one important factor responsible for their reduced efficiency on tasks requiring bimanual perceptuomotor coordination under a speed constraint.

Earlier studies (Jeeves, 1965) have shown that three acallosal Ss were slower at tasks requiring bimanual coordination than matched normals. The same patients did not show the deficits in interhemispheric transfer reported immediately to follow surgical section of the corpus callosum in adult life (Sperry, 1966, 1967, 1968; Gazzaniga, Bogen, \& Sperry, 1965). It was suggested that the reduced efficiency when performing tasks requiring bimanual coordination under a speed stress might be due, among other things, to increased interhemispheric transmission times in acallosals. In an attempt to explore this possibility, a comparison was made of ipsilateral and contralateral response times to visual stimuli falling only on the nasal part of the retina. These pilot studies (Jeeves, 1965) showed that the percentage increase of contralateral over ipsilateral response times in acallosals was greater than in small groups of matched normals. The studies reported below attempt to follow up this earlier exploratory study by accurately measuring the interhemispheric transmission times of acallosals and comparing them with normals.
Subjects made 60 responses under each of two different conditions at a session, i.e., a total of 120 , and came back for 5 successive days of testing under each stimulation condition, that is, nasal and temporal. For the temporal stimulation condition Ss wore a black plastic spectacle frame with lights embedded within the frame so that only the temporal part of a retina was stimulated when they flashed on. The same stimulus duration and variation in fore-periods were used as in the nasal condition. Thus, each $\mathrm{S}$ made a total of 300 responses under each of the two conditions, nasal and temporal.

Although the lights were manufactured as identical, in order to control for any slight undetected differences between them, in one experiment the lights were changed from one side to the other for half the Ss. This made no difference to the results obtained. Likewise, although the two morse keys were matched as carefully as possible, it was also decided to change them over for half the Ss in one experiment, but again this produced no effect upon the direction or magnitude of any of the observed differences. Using the two-handed responding technique, the interpretation of the observed differences between short- and long-pathway responding could be either as suggested above, i.e., as a measure of the time taken for sensory information to cross from one hemisphere to the other, or, alternatively, as the time taken for the hemisphere first responding to initiate a response in the other hemisphere. To eliminate the second possibility it was decided to run a further experiment in which Ss responded only with one hand. In this experiment all Ss made an equal number of responses with each hand. At an experimental sitting the $S$ would first make 60 responses with one hand and then, after a rest, a further 60 responses with the other hand. Under this condition, one is directly measuring transmission time for sensory information to pass from one hemisphere to the other.

In all experiments Ss were comfortably seated with their heads restrained in a hamess. The background illumination in the room was $32 \mathrm{ft}-\mathrm{c}$. The $\mathrm{E}$ with the control

Table 1

Comparison of Interhemispheric Transmission Times of Normals and Acallosals

\begin{tabular}{|c|c|c|c|c|c|c|c|}
\hline Ss & Condition & No. of Ss & $\begin{array}{l}\text { Part of retina } \\
\text { receiving } \\
\text { stimulation }\end{array}$ & $\begin{array}{l}\text { Mean } \\
\text { Short pathway } \\
\text { (SP) }\end{array}$ & $\begin{array}{l}\text { T for } \\
\text { Long pathway } \\
\text { (LP) }\end{array}$ & $\begin{array}{l}\text { Mean difference } \\
\text { between } \\
\text { LP and SP }\end{array}$ & $\begin{array}{c}\text { No. of Ss } \\
\text { showing LP } \\
\text { greater than SP }\end{array}$ \\
\hline $\begin{array}{l}\text { Right-handed } \\
\text { Right-handed } \\
\text { Left-handed } \\
\text { Left-handed } \\
\text { Right-handed } \\
\text { Right-handed } \\
\text { Acallosal boy } \\
\text { Age } 14 \\
\text { Acallosal man } \\
\text { Age } 46\end{array}$ & $\begin{array}{l}\text { Both hands responding } \\
\text { Both hands responding } \\
\text { Both hands responding } \\
\text { Both hands responding } \\
\text { Single hand responding } \\
\text { Single hand responding } \\
\text { Both hands responding } \\
\text { Both hands responding } \\
\text { Both hands responding }\end{array}$ & $\begin{array}{l}10 \\
10 \\
10 \\
10 \\
10 \\
10\end{array}$ & $\begin{array}{l}\text { Nasal } \\
\text { Temporal } \\
\text { Nasal } \\
\text { Temporal } \\
\text { Nasal } \\
\text { Temporal } \\
\text { Nasal } \\
\text { Temporal }\end{array}$ & $\begin{array}{l}271.09 \\
256.16 \\
243.85 \\
233.24 \\
234.99 \\
218.89 \\
346.5 \\
286.0\end{array}$ & $\begin{array}{l}272.89 \\
257.72 \\
245.50 \\
234.54 \\
237.55 \\
221.98 \\
365.0 \\
300.5\end{array}$ & $\begin{array}{l}+1.80 \\
+1.56 \\
+1.65 \\
+1.30 \\
+2.56 \\
+3.09 \\
+19.5 \\
+14.5 \\
+61.33\end{array}$ & $\begin{array}{r}8 \\
6 \\
10 \\
8 \\
8 \\
9 \\
- \\
-\end{array}$ \\
\hline
\end{tabular}


and recording apparatus was in an adjacent room. Response times were measured on two electronic timers accurate to $10^{-6} \mathrm{sec}$. Measurements were taken to the nearest millisecond.

\section{SUBJECTS}

The control groups of normal Ss were all male students aged 18-21 years. Ten were left-handed and 20 were right-handed. The two acallosal patients were selected from a group of 12 living in different parts of Australia and drawn to the author's attention by neurologist colleagues. The reasons for selecting these two for detailed study were (1) that they were able and willing to visit the laboratory for testing, and (2) because the neurologists' assessments made it highly probable that other cerebral abnormalities, other than the absence of the corpus callosum, were either totally or almost totally lacking. Detailed neurological reports of these patients, including pneumoencephalograms and ventriculograms, are given elsewhere (Jeeves, 1965), as also are details of basic psychometric testing. One was a boy of 14 years and the other a man of 46 years.

\section{RESULTS AND DISCUSSION}

Each $S$ made 300 responses with each hand under each of the two conditions of nasal and temporal retina stimulation. These responses were made to an equal number of stimuli presented in the right and left visual fields. Table 1 presents the mean response times for short-pathway and long-pathway responding for 30 normals and two acallosals. Ten of the normals were right-handed and responded with both hands, 10 were left-handed and responded with both hands, and a further 10 were right-handed and responded single-handedly. The acallosal boy came to the laboratory for testing for 5 days a week as did the normal Ss. The acallosal man lived 100 miles from the laboratory and was available for testing for one 3 -h period only, during a business visit to the city.

It is clear that all groups of normals gave shorter interhemispheric transmission times than the two acallosals. There were no differences between right- and left-handed Ss in ITTs. A comparison of the ITTs of the 20 normals and the two acallosals, under the nasal-stimulation/two-hands-responding condition, gave a Mann-Whitney $\mathrm{U}=0$, $\mathrm{p}<.01$ (one-tailed test). Referring to Table 1 , the results obtained when stimulating the nasal part of the retina show that the difference between short- and long-pathway responding for the three groups of normals, right-handed both hands responding, left-handed both hands responding, and right-handed single hand responding, were $1.80 \mathrm{msec}, 1.65 \mathrm{msec}$, and $2.56 \mathrm{msec}$, respectively. The comparable figures for the acallosal boy and the acallosal man were $19.5 \mathrm{msec}$ and $61.33 \mathrm{msec}$. When the temporal part of the retina was stimulated the figures for the same three groups of normals were $1.56 \mathrm{msec}$, $1.30 \mathrm{msec}$, and $3.09 \mathrm{msec}$, and for the acallosal boy, $14.5 \mathrm{msec}$. Again, comparing the 20 normal Ss on the two-handed condition with the acallosal boy, a Mann-Whitney $U=0, p=.05$ (one-tailed test) was obtained. No data under this condition were available for the acallosal man.

To test for the significance of the observed differences between short- and long-path way responding in the normals, the data for all groups were combined, making a total of $30 \mathrm{Ss}$. The difference scores between long and short pathway for nasal and temporal stimulation were then analyzed separately using a Wilcoxon matched-pairs signed rank test. This gave $\mathrm{z}$ (nasal) $=3.1$ $(\mathrm{p}<.001)$ and $\mathrm{z}$ (temporal $)=4.0(\mathrm{p}<.005)$. The interhemispheric transmission time for the acallosal man was unexpectedly long and one wonders whether the fact that he was the only $S$ who completed all his responding on one day had anything to do with this. Against this explanation is the fact that the greatly lengthened interhemispheric transmission time did not develop towards the end of the testing period, but was evident throughout. Moreover, his mean response time for short-pathway responding was within the range of performance of normal Ss. As regards the boy's lengthened interhemispheric transmission time, any attempt to explain this as being due solely to his being younger than the normal adult controls is ruled out by the finding that normal 10-year-old children show interhemispheric transmission times within the same range as the normal adults in this experiment.

The interhemispheric transmission time for the normals is within the range reported by earlier workers for the visual modality (Poffenberger, 1912), and for other modalities such as touch (Efron, 1963;
Moskatova, 1966). The interhemispheric transmission times for acallosals is so much greater than for the normals that one is left speculating as to what possible hemispheric pathway could take so long. If the alternate pathway is subcortical, it may, in addition to being longer than a transcallosal pathway, also be more diffuse and involve several additional synaptic junctions. Whatever specific speculations may be entertained concerning alternate interhemispheric pathways utilized by acallosal patients, the results reported above strengthen the earlier suggestion (Jeeves, 1965) that the reduced efficiency of acallosals on tasks involving bimanual perceptuomotor coordination under speed stress may be attributed partly to lengthened interhemispheric transmission times.

\section{REFERENCES}

EFRON, R. The effect of handedness on the perception of simultaneity and temporal order. Brain, 1963, 86, 261-284.

GAZZANIGA, M. S., BOGEN, J. E., \& SPERRY, R. W. Observations on visual perception after disconnexion of the cerebral hemispheres in man. Brain, 1965, 88, 221-236.

JEEVES, M. A. Psychological studies of three cases of congenital agenesis of the corpus callosum in man. In CIBA Foundation Study Group No. 20 (Eds.), Functions of the corpus collosum. London: Churchill, 1965. Pp. 73-94.

MOSKATOVA, A. K. Simple motor reaction time to tactile stimulation. Voprosy Psikhologii, $1966,2,68-74$

POFFENBERGER, A. T. Reaction time to retinal stimulation with special reference through nerve centres. Archives of Psychology, 1912, 23, 1 .

SPERRY, R. W. Brain bisection and mechanisms of consciousness. In J.C. Eccles (Ed.), Brain and conscious experience. New York: Springer-Veriag, 1966.

SPERRY, R. W., \& GAZZANIGA, M.S. Language following surgical disconnection of the hemispheres. In C. H. Millikan (Ed.), Brain mechanisms underlying speech and language. New York: Grune \& Stratton, 1967. Pp. 108-121.

SPERRY, R. W. Hemisphere deconnection and unity in conscious awareness. American Psychologist, 1968, 23, 723-733.

\section{The role of discontinuous US in discriminated avoidance learning '}

\section{G. B. BIEDERMAN, University of Toronto, Toronto, Ontario, Canada.}

A test of the hypothesis that responses in the off-cycle of discontinuous shock facilitates avoidance responding by generalization to the CS-US interval was performed by causing the stimulus conditions during the off-cycle to be dissimilar to the conditions in the CS-US interval. Avoidance performance was enhanced despite the stimulus differences, suggesting that the generalization hypothesis is incorrect. 